\title{
O processo educativo através de uma formação crítica e reflexiva: desafios e oportunidades
}

É comprovado que o aluno aprende melhor pela emoção, isto é, quando gosta e se envolve com o que está fazendo/aprendendo e nessa lógica o professor também precisa se entusiasmar com o que está ensinando. Através de uma pesquisa bibliográfica e documental o artigo tem o intuito de ponderar algumas questões sobre o uso de metodologias ativas nos processos de ensino e de aprendizagem. Essa emoção não nasce com a monotonia e com os métodos tradicionais ou regulares de ensino, mas sim com a novidade, com o respeito à forma específica que cada aluno tem de aprender, com a interação e com a reflexão. Fica evidente que o processo de aprendizagem que tange o conhecimento, não pode ser passível e submetido a um formato que pouco se adapta e agrada os nativos digitais. 0 professor continua sendo o elo entre a informação e o conhecimento e nunca perde a sua importância, porém, passa a ser um mediador que desenvolve a capacidade do aluno de aprender os conteúdos de forma autônoma e participativa, levando o aluno a uma formação crítica e reflexiva.

Palavras-chave: Processo educativo; Ensino; Aprendizagem; Inovação.

\section{The educational process through critical and reflective training: challenges and opportunities}

\begin{abstract}
It is proven that the student learns best through emotion, that is, when he likes and gets involved with what he is doing/learning and in this logic, the teacher also needs to be enthusiastic about what he is teaching. Through bibliographical and documentary research, the article aims to ponder some questions about the use of active methodologies in the teaching and learning processes. This emotion is not born with monotony and traditional or regular teaching methods, but with novelty, with respect for the specific way that each student has to learn, with interaction and reflection. It is evident that the learning process that concerns knowledge, cannot be passable and subjected to a format that digital natives do not adapt and like very much. The teacher remains the link between information and knowledge and never loses its importance, however, he becomes a mediator who develops the student's ability to learn the contents in an autonomous and participatory way, leading the student to a critical and reflective.
\end{abstract}

Keywords: Educational process; Teaching; Learning; Innovation.

Topic: Práticas, Didática e Metodologias do Ensino

Reviewed anonymously in the process of blind peer
Received: 19/04/2021

Approved: 20/07/2021
Patrícia Cristiane Franco (iD

Universidade de Passo Fundo, Brasil

http://lattes.cnpq.br/2871129766083868

http://orcid.org/0000-0003-3405-6304

patriciafrancohist@gmail.com

Vera Lúcia Trennenphol

Universidade Regional do Noroeste do Estado do Rio Grande do Sul, Brasil http://lattes.cnpq.br/3203877785058702

http://orcid.org/0000-0003-4167-7512

veral.trennepohl@gmail.com

Tarcísio Dorn de Oliveira (iD

Universidade Regional do Noroeste do Estado do Rio Grande do Sul, Brasil http://lattes.cnpq.br/1493478586678556

http://orcid.org/0000-0001-5842-2415

tarcisio_dorn@hotmail.com
Daniel Hedlund Soares das Chagas

Universidade Federal de Santa Maria, Brasil

http://lattes.cnpq.br/9367990204769757

http://orcid.org/0000-0002-5253-3832

danielhedlund13@hotmail.com
Referencing this:

FRANCO, P. C.; TRENNEPOHL, V. L.; OLIVEIRA, T. D.; CHAGAS, D. H. S. $O$ processo educativo através de uma formação crítica e reflexiva: desafios e oportunidades. Educationis, v.9, n.2, p.51-56, 2021. DOI: http://doi.org/10.6008/CBPC2318-3047.2021.002.0006 


\section{INTRODUÇÃO}

Na fábula, a rã era manca, porém, se declarava conhecedora da cura de todos os males, ao que chega a raposa e lhe sugere, através de seu questionamento, curar primeiramente a sua própria deficiência, de modo que somente assim, poderia pensar em curar os outros. Assim, ocorre com os professores que exigem dos alunos, habilidades que não possuem ou não procuram desenvolver. Para que este possa criar e inserir em aula, metodologias ativas que incentivem a pesquisa e a prática da reflexão, é necessário SER um pesquisador e entusiasta de sua teoria.

"Certa vez, havia num brejo uma rã que gritava para todos os animais: "Eu sou médica, especialista em todos os tipos de remédios!". Ao ouvi-la, disse uma raposa: "Se você, que manquitola, não cura sua própria deficiência, como é que vai salvar os outros?" (Esopo Fábulas Completas)

O processo educativo presume que quem ensina supera em conhecimento aquele que está aprendendo, pois, a questão de o professor ser um imigrante digital frente ao nativo digital, faz com que esse educador necessite de coragem e vontade para aprender a nova língua, pesquisando de forma autônoma, juntamente e/ou paralelamente ao seu aluno, mas sem ultrapassar a linha que o coloca como a autoridade responsável pelo processo de educar.

Conforme Demo (2015), a pesquisa precisa ser uma prática cotidiana na vida do professor, através da constante revisão e reconstrução do seu saber pedagógico. Ter um projeto pedagógico próprio, cuja dinâmica e metodologia sejam de profundo conhecimento e domínio é indispensável ao profissional do saber. Esse projeto deve ter a pesquisa como princípio educativo, além de um compromisso com o desempenho do aluno. Não deve ser fechado em determinadas correntes teóricas ou ideológicas, mas sim, usar de um processo democrático e livre para reflexão, unindo teoria e prática no cotidiano escolar.

Ao repensar as metodologias de ensino, novas formas são apresentadas, entre elas, várias alternativas que englobam as TIC's ou simplesmente colocam o aluno em uma situação desafiadora, tirandoo da passividade que a educação bancária os remete. É necessário fazer com que o processo educativo seja adequado ao perfil desse aluno que não se contenta com a preleção do professor, mas necessita da interação e da prática.

Mas o que se entende por metodologias ativas? No que elas diferem dos métodos tradicionais de ensino a que estamos acostumados? Para compreender de fato, vale lembrar que todo plano de aula ou projeto pedagógico começa com um objetivo claro, que precisa ter sua viabilidade avaliada, bem como o seu propósito e a sua prioridade. As metodologias são formas de ação que se utilizam das mais diversas ferramentas tecnológicas ou não, com as quais teremos esse objetivo posto em prática. É através das metodologias de ensino que se dará a conexão entre professor e aluno e a construção da aprendizagem.

\section{METODOLOGIA}

O presente estudo compõe-se de uma pesquisa básica com revisão bibliográfica. A partir dos dados obtidos, realizou-se a análise e interpretação das informações, mesclando-as de maneira a conseguir uma maior compreensão sobre o tema abordado. 


\title{
DISCUSSÃO TEÓRICA
}

As metodologias ativas, são pensadas com base teórica, mas se concentram mais no campo da ação, pois são avaliadas e pensadas de acordo com o perfil dos alunos em questão. São práticas pedagógicas que levam o estudante a pensar, refletir e agir e não apenas receber um conteúdo passivamente e decorá-lo para a prova avaliativa.

Elas permitem que o estudante discuta, escreva, leia, solucione problemas e ensine os outros colegas, através de métodos que podem ser melhorados com uso das mais diversas ferramentas. São ferramentas utilizadas para o fazer de atividades de experimentação, aprendizagem baseada em projetos ou em problematizações. As mais variadas formas de metodologias aplicadas através do uso das mais diversas ferramentas, são válidas e necessárias para tirar professor e aluno de suas zonas de conforto e qualificarem o processo educativo. Demo (2015) sugere que o professor pesquise constantemente o tema de cada aula, a fim de se manter atualizado e em busca constante de inovação:

\begin{abstract}
Vale como regra que não se pode fazer nada em sala de aula que não tenha sido antes devidamente pesquisado e formulado. (...). É sobretudo a reconstrução permanente dos conteúdos e procedimentos didáticos, de tal sorte que qualquer aluno perceba, com clareza insofismável, que está diante de agente de inovação, com qualidade formal e política. Preocupação crucial será cultivar a proximidade entre o que se aprende na escola, com a vida real, não só por conta da possível utilidade imediata, nem sempre muito visível, mas sobre tudo por conta da relação entre teoria e prática, ou entre qualidade formal e política. Mais do que nunca, deve ficar claro que o conhecimento reconstruído é a base da inovação, não só na cabeça, mas igualmente na vida concreta. (DEMO, 2015)
\end{abstract}

Para ensinar, o professor precisa ser dotado de um conjunto de competências. A pesquisa como eixo fundamental e seguida pela capacidade de elaboração própria; teorização das práticas; atualização permanente; bem como o manejo eletrônico. O manejo eletrônico se faz necessário, então, para a construção do seu próprio conhecimento, em forma de ferramenta e em forma de linguagem ao se relacionar com o nativo digital. Freire (2018), nos dá uma importante lição a respeito da natureza da prática docente:

Não há ensino sem pesquisa. Esses quefazeres se encontram um no corpo do outro. Enquanto ensino continuo buscando, reprocurando. Ensino porque por que busco, porque indaguei, porque indago e me indago. Pesquiso para constatar, constatando, intervenho, intervindo educo e me educo. Pesquiso para conhecer o que ainda não conheço e comunicar ou anunciar a novidade. (FREIRE, 2018)

Assim como o aluno é curioso, a natureza docente também deve compartilhar desse sentimento. 0 professor deve ser a antena que capta as mudanças do seu tempo porque é o profissional mais próximo das novas gerações e com isso, pode manter-se com o espírito 'jovem', sendo essa talvez, a grande gratificação da profissão.

A curiosidade epistemológica, como definiu Freire (2018), é a inquietação indagadora ingênua levada ao campo da epistemologia, que nos torna criativos e críticos. Captar, pesquisar e compartilhar as novidades com a sabedoria de quem já viveu um pouco mais deve ser ação permanente da profissão docente. A pesquisa do educador e o estímulo à pesquisa do educando demonstram o compromisso com a consciência crítica, pois a "promoção da ingenuidade não se faz automaticamente" (FREIRE, 2018). Ser professor exige coerência entre o discurso e a prática. 
Ao adentrar a escola pela primeira vez, o futuro docente sente-se inseguro e assustado com o tamanho da responsabilidade com a qual se depara, pois têm a teoria, mas nada conhece da prática. Já os alunos da educação básica, seja da faixa etária que for, são curiosos e críticos e trazem para a sala de aula, muito mais do que a necessidade do saber escolar, mas a inquietude e as descobertas da vida. Como lidar com a curiosidade desses alunos? Se ater ao conteúdo ou aproveitar cada 'deixa' para sanar suas dúvidas? Cada professor tem a opção de escolher o que achar conveniente.

Nesse ponto, ficamos com a segunda opção, por que de certa forma ela me permite defender os argumentos expostos até aqui. “Um dos saberes fundamentais a minha prática educativo-crítica é o que me adverte da necessária promoção da curiosidade espontânea para a curiosidade epistemológica" (FREIRE, 2018). É na curiosidade que há o impulso para a educação.

A insegurança, portanto, vai embora e dá lugar ao prazer da contribuição na formação desses alunos. É importante ouvir os alunos e o quanto de afeto está intimamente ligado ao estímulo de ensinar e aprender. A aula não pode ser um mero repasse de conhecimento, mas uma troca, uma prática engajada na autonomia do aluno e na transgressão de paradigmas já ultrapassados. Como já sabemos por Freire (2015):

A nossa capacidade de aprender, de que decorre a de ensinar, sugere ou, mais do que isso, implica a nossa habilidade de aprender a substantividade do objeto aprendido. A memorização mecânica do perfil do objeto não é aprendizado verdadeiro do objeto ou do conteúdo. Neste caso, o aprendiz funciona muito mais como paciente da transferência do objeto ou do conteúdo do que como sujeito crítico, epistemologicamente curioso, que constrói o conhecimento do objeto ou participa de sua construção. (FREIRE, 2015)

Fazer com que o aluno se entenda como participante do processo de construção da sociedade em que vive e que tenha condições para isso, é o papel de todo educador. Ensinar é também propagar esperança nessa construção pois, segundo Freire (2015), "sem ela, não haveria história, mas puro determinismo. Só há história onde há tempo problematizado e não pré-dado. A inexorabilidade do futuro, é a negação da história". Propagar esperança e afeto deve ser atividade fundamental do professor que anseia que seu aluno aprenda, além do conteúdo específico, valores para a vida.

Como percebe-se, nem tudo sai como no plano de aula inicial, mas com tudo se aprende. Eis que o professor deve saber adaptar-se sem ser um conformista. A experiência docente é uma tarefa que exige adaptação, entendimento da realidade, humildade, tolerância e disposição para a mudança. Não é uma tarefa para grandes e envaidecidos egos. É preciso gostar de gente, de transformar e ser transformado pelo diálogo com a complexidade humana.

O Brasil apresenta um contexto educacional, na esfera pública, difícil de assimilar com metodologias inovadoras, ainda mais quando estas sugerem uso de tecnologia. Bem sabemos também, que a falta de estrutura, seja física, familiar ou social, muitas vezes impedem as boas práticas e podam a boa vontade dos professores. Faltam recursos financeiros, falta investimento em formação continuada do corpo docente, falta valorização da categoria profissional e muitas vezes, falta respeito. Nosso país lidera o ranking de violência contra o professor:

De acordo com dados de uma pesquisa feita pela Organização para a Cooperação e Desenvolvimento Econômico (OCDE) sobre violência em escolas com mais de 100 mil professores, o Brasil lidera o ranking de agressões contra docentes. Dentre os professores 
ouvidos, $12,5 \%$ afirmaram ser vítimas de agressões verbais ou intimidações de alunos. (...) Professores de São Paulo apontam que mais da metade dos docentes da rede estadual de ensino afirmam já ter sofrido algum tipo de agressão, sendo a mais comum a agressão verbal (44\%), seguida por discriminação (9\%), bullying (8\%), furto/roubo (6\%), e agressão física (5\%). (D'AGOSTINI, 2019)

Sabemos que as pessoas se tornam verdadeiramente humanas quando interagem com outras, vivendo com elas em grupos sociais. A escola, depois da família, é o principal grupo social na vida de uma criança ou adolescente; é onde o indivíduo adquire conhecimentos científicos e que serão necessários para uma profissão futura; onde desenvolverá suas potencialidades; onde passa a se conhecer como membro de uma sociedade e de uma cultura e ao mesmo tempo onde criará uma identidade individual. Porém, com todas as dificuldades existentes, não é possível desistir do aluno, por que ele é fruto das nossas próprias ações como sociedade. Somos todos responsáveis pela atuação dessa nova geração, sendo que nem a família e nem a escola podem abrir mão de seus deveres.

A educação não é um processo de aprendizagem passivo. A medida que cresce, seu processo educativo vai adquirindo complexidade e enquanto aprende, o aluno reage com atitudes e formas de sentir e pensar que exercem influência na sua própria educação; afetam a família e a sociedade, ou seja, o aluno não é somente o objeto do processo educativo, mas também o sujeito.

Ao futuro professor, serão necessárias adaptações a falta de estrutura física, mas também estratégias para vencer determinadas barreiras culturais. São muitos os desafios da prática docente, que exigem disposição e afeto. E com todas as dificuldades, Karnal (2012) nos lembra que:

Há algo que valia na Academia de Platão ou no Liceu de Aristóteles e vale hoje, no século XXI: uma boa aula é aquela que faz pensar, provoca reflexão e traz, com isso, uma nova percepção das coisas. (...) O elemento central de uma boa aula envolve o conhecimento já formado (vocabulário, procedimentos, habilidades etc.) e sua interação com novos procedimentos do aluno. Uma boa aula transforma quem se envolve nela. Sempre é bom repetir: uma boa aula não precisa de tecnologia. A tecnologia é uma ferramenta privilegiada, jamais o objetivo em si. O computador funciona como uma alavanca: move melhor a pedra pesada, mas o objetivo continua sendo mover a pedra. (KARNAL, 2012)

São muitas as pedras, mas o caminho é gratificante para o professor e libertador para o aluno. Falar a mesma linguagem dos alunos não é dar uma aula impregnada de gírias, mas uma aula que seja tão dinâmica quanto a vida desses jovens é fora da escola. É seduzir pela proximidade e pelo afeto. É acompanhar as mudanças e se inserir nelas. Se o aluno gosta de fotografar e expõe tudo o que vê, vamos trabalhar com a fotografia. Se o aluno utiliza muito as redes sociais, vamos trabalhar textos clássicos passando-os para a linguagem do twitter. Se gosta de música para estudar, que estude a ditadura de 1964, ouvindo músicas de protesto dessa época. Computadores não devem ser demonizados e nem idolatrados, mas inseridos no contexto conforme as possibilidades, afinal, a única coisa que não se pode nunca, é ignorar as mudanças quando batem a nossa porta.

\section{CONCLUSÕES}

Vivenciar a Revolução Tecnológica exige participação. Ninguém consegue ficar alheio às mudanças que ocorrem no tempo presente, simplesmente pelo fato de que somos sujeitos históricos, frutos de um 
passado e semeadores de um futuro. O contexto atual coloca imigrantes e nativos digitais dentro da mesma sala de aula e o que torna essa relação complexa é o fato de que são os imigrantes que precisam e devem ensinar o nativo as bases do conhecimento científico, oportunizando o desenvolvimento cognitivo e o convívio social.

O professor tem um papel fundamental dentro da sociedade por ser o formador de todas as outras profissões. O seu processo de formação inicial também precisa ser pensado e repensado a todo momento, visto que as mudanças são constantes e velozes. Bem vimos que os conceitos da educação tradicional já formam sobrepujados e logo mais, as atuais metodologias também serão superadas. A participação da neurociência na educação será cada vez mais necessária, justamente por que as tecnologias estarão cada vez mais enraizadas e ativas no seio social e individual do aluno. Tecnologicamente não haverá retrocesso e não podemos permitir que haja na educação.

Também não podemos esquecer de mencionar que educar é um ato político. Ensinar os alunos a "lerem o mundo", como dizia Freire (2015), não pode ser feito sem ideologia. É uma ilusão pensar e exigir uma total imparcialidade da figura do professor. Nenhum profissional é imparcial. Estamos o tempo todo observando, indagando e buscando soluções para uma realidade que ora nos agrada e ora não, por que é impossível sermos indiferentes à nossa realidade.

A natureza humana é de uma total complexidade e isso não foge a figura do professor. E é nessas mais diversas visões e posicionamentos que o aluno encontrará o seu caminho; o seu pensar. O que realmente importa é que a educação seja libertadora, ou seja, que o professor permita que o aluno pense, dialogue, critique, mas também aprenda a ouvir o colega que tem uma visão diferente da sua.

O professor precisa manter a sua autoridade pelo seu conhecimento, mas também construir uma relação de afinidade com seu aluno; ser a figura positiva que conhece e acredita no seu potencial, investe tempo e conhecimento na sua qualificação. Saber que pode fazer a diferença ou interferir no modo como esse aluno olhará para a sua vida e o seu futuro deve servir de estímulo para o professor, ao tirar as ideias inovadoras do pensamento abstrato e transformá-las em uma educação de qualidade, progressista e esperançosa.

\section{REFERÊNCIAS}

D'AGOSTINI, A. C. C.. Brasil lidera índice de violência contra professores. O que podemos fazer?. NOVA ESCOLA, 2019.

DEMO, P.. Educar pela Pesquisa. 10 ed. Campinas: Autores Associados, 2015.
FREIRE, P.. Pedagogia da Autonomia. 57 ed. São Paulo: Paz e Terra, 2018.

KARNAL, L.. Conversas com um jovem professor. São Paulo: Contexto, 2012.

A CBPC - Companhia Brasileira de Produção Científica (CNPJ: 11.221.422/0001-03) detém os direitos materiais desta publicação. Os direitos referem-se à publicação do trabalho em qualquer parte do mundo, incluindo os direitos às renovações, expansões e disseminações da contribuição, bem como outros direitos subsidiários. Todos os trabalhos publicados eletronicamente poderão posteriormente ser publicados em coletâneas impressas sob coordenação da Sustenere Publishing, da Companhia Brasileira de Produção Científica e seus parceiros autorizados. Os (as) autores (as) preservam os direitos autorais, mas não têm permissão para a publicação da contribuição em outro meio, impresso ou digital, em português ou em tradução. 